\title{
Reports of Perceived Adverse Events of Stimulant Medication on Cognition, Motivation, and Mood: Qualitative Investigation and the Generation of Items for the Medication and Cognition Rating Scale
}

\author{
Hanna Kovshoff, PhD, ${ }^{1}$ Tobias Banaschewski, MD, PhD, Jan K. Buitelaar, MD, PhD, Sara Carucci, MD, \\ David Coghill, MBChB, MD, FRCPsych, ${ }^{5,6}$ Marina Danckaerts, MD, PhD, Ralf W. Dittmann, MD, PhD, \\ Bruno Falissard, MD, PhD ${ }^{9}$ Dina Gojkovic Grimshaw, PhD, ${ }^{1}$ Chris Hollis, PhD, FRCPsych, ${ }^{10}$ \\ Sarah Inglis, PhD, ${ }^{11}$ Kerstin Konrad, PhD, ${ }^{12,13}$ Elizabeth Liddle, PhD, ${ }^{10}$ Suzanne McCarthy, PhD, ${ }^{14}$ \\ Peter Nagy, MD, ${ }^{15}$ Margaret Thompson, MD, FRCPsych, lan C.K. Wong, PhD, FRCPCH, ${ }^{16,17}$ \\ Alessandro Zuddas, $\mathrm{MD}^{4}$, and Edmund J.S. Sonuga-Barke, $\mathrm{PhD}^{1,18}$
}

\begin{abstract}
Objective: There is no questionnaire to specifically monitor perceived adverse events of methylphenidate (MPH) on cognition, motivation, and mood. The current study therefore had two goals. First, to harvest accounts of such putative events from transcripts of interviews in samples enriched for such potential experiences. Second, to use the derived data to generate items for a new questionnaire that can be used for monitoring such events in medication trials or routine clinical care.

Methods: Following a literature search aimed at identifying associations between MPH and cognition and/or motivation, a qualitative semistructured interview was designed to focus specifically on the domains of cognition (i.e., reasoning, depth/ breadth of thinking, intellectual capacity, and creativity) and motivation (i.e., drive, effort, and attitudes toward rewards/ incentives). Interviews were conducted with 45 participants drawn from the following four groups: (a) clinicians, child and adolescent psychiatrists, and pediatricians specializing in attention-deficit/hyperactivity disorder (ADHD) $(n=15)$; $(2)$ teachers, with experience of teaching at least 10 medicated children with ADHD $(n=10)$; (3) parents of children with ADHD $(n=8)$ treated with MPH; and (4) adolescents/adults with ADHD $(n=12)$. Purposeful sampling was used to selectively recruit ADHD participants whose histories suggested a degree of vulnerability to MPH adverse events. Data were analyzed using a deductive approach to content analysis.

\footnotetext{
${ }^{1}$ Academic Unit of Psychology, University of Southampton, Southampton, United Kingdom.

${ }^{2}$ Department of Child and Adolescent Psychiatry and Psychotherapy, Central Institute of Mental Health, Medical Faculty Mannheim, University of Heidelberg, Mannheim, Germany.

${ }^{3}$ Radboud University Medical Centre, Donders Institute for Brain, Cognition and Behavior, Department of Cognitive Neuroscience \& Karakter Child and Adolescent Psychiatry University Centre, Nijmegen, the Netherlands.

${ }^{4}$ Child and Adolescent Neuropsychiatry Unit, Department of Biomedical Science, University of Cagliari, Italy.

${ }^{5}$ Division of Neuroscience, School of Medicine, University of Dundee, Dundee, United Kingdom.

${ }^{6}$ Departments of Paediatrics and Psychiatry, Faculty of Medicine, Dentistry and Health Sciences, University of Melbourne, Australia.

${ }^{7}$ Department of Neurosciences, Research Group Psychiatry, KU Leuven, Belgium.

${ }^{8}$ Paediatric Psychopharmacology, Department of Child and Adolescent Psychiatry and Psychotherapy, Central Institute of Mental Health, Medical Faculty Mannheim, University of Heidelberg, Germany.

${ }^{9}$ INSERM U1178, University Paris-Sud, University Paris-Descartes, AP-HP, Paris, France.

${ }^{10}$ Institute of Mental Health, Faculty of Medicine and Health Sciences, University of Nottingham, United Kingdom.

${ }^{11}$ Tayside Clinical Trials Unit, University of Dundee, Dundee, United Kingdom.

${ }^{12}$ Clinical Child Neuropsychology, Department of Child and Adolescent Psychiatry, Psychosomatics, and Psychotherapy, University Hospital RWTH Aachen, Aachen, Germany.

${ }^{13}$ Institute of Neuroscience \& Medicine (INM3), Research Centre Juelich, Germany.

${ }^{14}$ School of Pharmacy, University College Cork, Cork, Ireland.

${ }^{15}$ Vadaskert Child and Adolescent Psychiatric Hospital, Budapest, Hungary.

${ }^{16}$ UCL School of Pharmacy, London, United Kingdom.

${ }^{17}$ Department of Pharmacology and Pharmacy, Li Ka Shing Faculty of Medicine University of Hong Kong, China.

${ }^{18}$ Department of Experimental Clinical \& Health Psychology, Ghent University, Ghent, Belgium.

(c) Hanna Kovshoff et al. 2016; Published by Mary Ann Liebert, Inc. This Open Access article is distributed under the terms of the Creative Commons Attribution Noncommercial License (http://creativecommons.org/licenses/by-nc/4.0/) which permits any noncommercial use, distribution, and reproduction in any medium, provided the original author(s) and the source are credited.
} 
Results: While we probed purposefully for cognitive and motivational adverse events, a third domain, related to mood, emerged from the reports. Therefore, three domains, each with a number of subdomains, were identified from the interview accounts: (i) Cognition (six subdomains; attention/concentration, changes in thinking, reduced creativity, sensory overload, memory, slower processing speed); (ii) motivation (four subdomains; loss of intrinsic motivation for goal-directed activities, external locus of control, lack of effort/engagement in daily tasks, increased focus on incentives); and (iii) mood (three subdomains; dampening of spontaneity/flat affect, mood dysregulation, increased anxiety/edginess). On the basis of these reports, 34 items were specified and incorporated into a prototype questionnaire, which was piloted and refined on the basis of field-testing.

Conclusions: Items were identified that capture potential/perceived cognitive, motivational, and mood-related adverse events of MPH. The items generated will allow us to further develop and psychometrically examine their prevalence, and the extent to which they are associated with medication adherence, treatment outcome, impairment, and other reported adverse events (e.g., loss of appetite/cardiovascular effects).

\section{Introduction}

$\mathbf{M}$ ETHYLPHENIDATE (MPH), along with other stimulant and nonstimulant medications, is recommended for the treatment of attention-deficit/hyperactivity disorder (ADHD) based on evidence of efficacy from randomized controlled trials (NICE 2008; Graham et al. 2011). While generally well tolerated (Faraone and Buitelaar 2010), MPH has been associated with a range of adverse events/ reactions over both the short and medium/long term (Cortese et al. 2013). The most common of these include loss of appetite, restricted growth, and weight suppression (Faraone et al. 2008), increases in blood pressure and heart rate (Graham and Coghill 2008; Hammerness et al. 2011), sleep disturbances (Schachter et al. 2001), and possible exacerbation of existing tics (Pringsheim and Steeves 2011).

Short-term positive effects of MPH on cognition and motivation are well documented in neuropsychological studies (Volkow et al. 2004; Coghill et al. 2014). Stimulant medication may improve some cognitive functions (attention), but there are also reports that it impairs others such as divergent thinking (Douglas et al. 1995), flexibility and planning (Advocat 2010), or creativity (Farah et al. 2008), at least in some cases. In terms of adverse events, laboratory studies provide some evidence of cognitive rigidity (Solanto 1984), reward desensitization (Andersen et al. 2008), altered attribution style/sense of agency (Carlson et al. 1993), and/or impaired memory (Sprague et al. 1977) with some of these cognitive changes being dose dependent such that higher doses lead to more impairing adverse events.

Consistent with this notion, there are also reports in the literature of higher doses of MPH being more effective for behavioral management but impacting negatively on executive attention control and working memory (Berridge et al. 2006). Thus, if clinicians and families prioritize behavioral targets in treatment goals, this may limit the potential impact of MPH on academic achievement more generally, given the lower doses required for cognitive enhancement (c.f., Hale et al. 2011). Finally, there have also been reports of adverse emotional events (e.g., Pelham and Hoza 1996), which are known to play a role in both cognitive ability and motivational style.

While there are some reports that adverse events of MPH may manifest as changes in cognition and motivation, these may not be mentioned or questioned in the course of routine clinical practice. Regulatory bodies like the European Medicines Agency (EMA 2010) require the monitoring and collection of pharmacovigilance data, which involves the monitoring of medication effects after licensing for adverse effects not reported or found in clinical trials. These data are required to be collated for potential adverse effects/ events during the clinical development of psychotropic compounds and through postmarketing surveillance for up to 2 years in adult and pediatric populations. However, it is not well understood how consistently cognitive adverse events are reported once the regulatory monitoring and reporting period for the medication has ended (post-2 years for ADHD medication) as it depends on clinicians and patients spontaneously identifying and reporting these as adverse events or side effects (e.g., through yellow card reporting in the UK-MHRA 2015).

While typical acute adverse effect scales for stimulant treatments such as the Safety Monitoring Uniform Report Form (SMURF; Greenhill et al. 2004) or the Side Effects Scale (Barkley et al. 1990) collate information such as "stares a lot," "talks less,", "prone to crying," "anxious," or "sadness," detailed standardized assessments of potential adverse events of MPH across broader psychological domains-for instance, those relating to cognition, motivation, and mood-are still lacking. Nevertheless, this may be of particular importance as it has been suggested that cognitive, motivational, and emotional adverse events are significant reasons for lack of adherence with, or discontinuation of, long-term medication use, particularly during adolescence (Charach et al. 2004, 2008).

The lack of routine monitoring of cognitive and motivational adverse events in everyday clinical practice could be linked to a more general lack of systematic monitoring of treatment response, as many clinicians still rely on spontaneous reporting of adverse events by patients and parents (Kovshoff et al. 2012). It is also likely due to the fact that compared to other elements of the putative MPH adverse event or effect profile, the concept of cognitive or motivational adverse events remains both poorly defined and articulated, with no standardized approach to reporting available.

Other potential reasons for the lack of focus on cognitive and motivational adverse events include that (i) they may be more difficult to observe than typical adverse events; (ii) they might be experienced as subtle and/or vague signs that are difficult to describe and self-report, particularly by younger children; (iii) they may be rare; (iv) it may be difficult to establish a causal link (if one exists) between these adverse events and the medication, or to differentiate between concerns specific to MPH and core or secondary symptoms of the ADHD itself; or (v) the benefits of MPH experienced by the patient and families may outweigh any potential cognitive or motivational adverse events experienced, and hence, these adverse events may not be seen as sufficiently significant to warrant reporting.

The current article represents the first stage in a project to investigate cognitive and motivational adverse events following stimulant medication use as part of the European Commission 7th Framework Programme for research; Attention Deficit/hyperactivity Drugs Use Chronic Effects (ADDUCE; www.adhd-adduce. org-Grant no. 260576) (Murray et al. 2013; Inglis et al. 
submitted). Within this larger program of research, one subproject involved the development of a questionnaire to systematically measure putative cognitive and motivational adverse events following MPH treatment. This will eventually allow us to estimate the prevalence of such effects in the general population of individuals treated with MPH, explore the association with adherence and treatment outcome, and assess their impact on daily functioning.

\section{Aims and Objectives}

The goal of this study was to generate items that characterize potential adverse events that may be associated with MPH as perceived by the patient, family, clinicians, or teachers that impact on cognition and/or motivation. Our aim was to elicit examples of potential adverse cognitive and motivational events that, at least to our participants, were believed to be associated with MPH treatment, so that these accounts could provide candidate items for a questionnaire that could then be validated in a larger representative sample. We first aimed to collect multiple examples and experiences of cognitive and motivational adverse events, including the key stakeholder groups in ADHD management (i.e., children and adults with ADHD, parents of children with ADHD, teachers, and clinicians). The views and experiences described were then transformed into items that could be used to elicit quantifiable responses on a questionnaire. The questionnaire was then piloted in a group of children with ADHD and subsequently refined to ensure acceptability and accessibility of items and concepts.

\section{Methods}

\section{Participants}

The research protocol and all study documents received University of Southampton (ERGO Study ID 681; RGO Ref 8377) and NHS Research Ethics Committee (REC Study ID: 11/SC/0541) approval. Within this protocol, all participants were provided with information sheets describing the aims and objectives of the study, given the opportunity to reflect and ask questions about participation, and signed consent or assent forms describing how their interview data would be used. They were also provided with debrief forms outlining how to withdraw from the study if desired, obtain a copy of the findings when the study was complete, and signposting to additional services if required.

To maximize the chances of identifying a range of potential cognitive and motivational experiences associated with MPH treatment, and to ensure that we were able to saturate our data, purposeful sampling of four independent groups of approximately 8-12 participants each, were recruited from within the South of England; experienced ADHD clinicians, adults and adolescents with ADHD who self-identified as having experienced unwanted adverse events when taking MPH, parents of children with ADHD who self-reported that their child experienced unwanted adverse events when taking MPH, and experienced teachers of medicated children with ADHD (e.g., from special needs classes, pupil referral units). Thus, all of the participants had personal or professional experience with and/or history of general MPH adverse events.

The group of clinicians ( $n=15$; 9 females, 6 males) with professional experience of treating ADHD consisted of six pediatricians, seven child and adolescent psychiatrists, and two senior nurse prescribers specializing in ADHD. They were included in the study if they had a minimum of 5 years experience of prescribing MPH to patients with ADHD and opportunities for the follow-up consulta- tions where they would have had a chance to examine potential adverse effects. The mean length of experience of MPH prescribing was 12.0 years (standard deviation $[\mathrm{SD}]=6.6$ ). Individuals with ADHD ( $n=12 ; 7$ females, 4 males, 1 preferred not to disclose) included three adolescents (ages $12-17$ years, mean age 14.6 years, $S D=2.5$ ) and nine adults who had undergone relatively extended treatment (i.e., more than 12 months of consecutive use) with MPH and selfreported experiencing adverse events when taking the medication.

For parents of patients/individuals with $\operatorname{ADHD}(n=8 ; 7$ females, 1 male), inclusion criteria stipulated that they had a child who had experienced evident adverse events while taking MPH (either past or present, we included any form of event that was deemed unwanted or adverse in the eyes of patients or families). Teachers ( $n=10$; 6 females, 4 males) who had significant experience of teaching MPH-treated children with ADHD (min. 10 children) were also interviewed. They had a mean duration of 6.4 years $(\mathrm{SD}=3.9)$ working with medicated children with ADHD. To ensure confidentiality, participants were ascribed unique anonymized identifiers. These consisted of a letter referring to the category to which they belonged $(\mathrm{C}=$ clinicians, $\mathrm{P}=$ parents, $\mathrm{T}=$ teachers, $\mathrm{AC}=$ individuals with $\mathrm{ADHD}$ ) and a number (e.g., $\mathrm{C} 1$ for Clinician number 1). We recorded interviews and transcribed and coded them immediately after interviewing the participants so that we were able to sample to saturation (i.e., the point at which no new codes were returned from the interview transcripts).

\section{Interview procedure}

The semistructured interview was developed by the research team to include open-ended questions about potential cognitive and motivational adverse events perceived to be directly related to MPH (e.g., could you describe any positive/negative effect of MPH on your thinking). After piloting the original interview schedule with three participants, including one medicated adult with ADHD, one clinician, and one parent of an adolescent with ADHD, the final interview schedule comprised a total of 34 questions focusing on cognitive $(n=17)$ and motivational $(n=17)$ adverse events. Interviewers encouraged participants to describe any potential adverse events in their own words. When describing an experience, interviewers took care to clarify whether the participant believed the experience only appeared after or worsened since starting MPH.

The participants were informed that the study was exploratory and that the aim was to shed light on any cognitive and/or motivational adverse events, which they may have noticed in their professional practice and/or personal experience of MPH. Interviews were conducted by postdoctoral-level researchers who had been trained to conduct qualitative interviews and had extensive experience in this technique. Interviews typically lasted for 60 minutes and occurred at a time and place that was convenient for participants (e.g., home, place of work, or through telephone).

\section{Data analysis}

A content analysis approach to the data (Ritchie and Spencer 1993) was used as it provides a flexible and deductive method for analyzing text data. For the current study, conventional content analysis was used through which coding categories were derived directly from the text (Hsieh and Shannon 2005). While our interview was designed to gather information about positive and negative effects of MPH, given our overall aim was to develop a questionnaire measure of adverse events, only negative/adverse experiences/events of MPH treatment were coded. 
In the first phase, two researchers familiarized themselves with the transcripts through a thorough reading from beginning to end. Then, the researcher who performed the main analysis read each transcript carefully again, making notes, and highlighting the text that described the adverse events of medication in the predetermined areas of cognition and motivation (e.g., memory, attention, and creativity). The researcher then generated preliminary codes from the first five transcripts from each participant group and coded the remaining transcripts using these original codes, adding new codes whenever new information was encountered that did not fit in with the existing codes.

While coding, the researcher collapsed or combined lower level codes to form higher level codes (for instance, "inability to take in others," "point of view," and "fixation on thoughts/actions" were combined into higher level code "rigidity of thought," which then formed part of "top-level" code "changes in thinking"). During this process, a complete detailed coding manual devised by the first coder was scrutinized by the second. The second researcher independently recoded $10 \%$ of the transcripts, effectively retesting all of the codes. Any differences between the codings were discussed until a mutual agreement on the final coding manual was achieved.

\section{Results}

\section{Categories, domains and subdomains}

Overall, at least one cognitive and/or motivational adverse experience of MPH was reported by $89 \%$ of participants interviewed in this study (note that this figure does not relate to prevalence rates of adverse events in the general ADHD population treated with stimulants, but only in our highly selective purposeful sample). Table 1 provides a summary of domains and subdomains by category listed in order of frequency of report/nomination by participants (in descending order from the most commonly identified adverse experience/event with the medication), alongside a prototypical statement and illustrative quote for each.

During the analysis stage, a third category of "mood"-related adverse events was added although it was not specifically probed in the study. A total of $84 \%$ of participants were described cognitive, $80 \%$ mood related, and $51 \%$ motivational adverse events. A detailed breakdown of these figures by category and participant group is shown in Table 1. Table 2 represents a summary of categories and domains.

Cognitive. Cognitive AEs were most commonly reported. Six domains emerged, ordered according to frequency; (1) poorer attention/concentration, (2) changes in thinking, (3) reduced creativity, (4) sensory overload, (5) poorer memory, and (6) slower processing speed. (1) Negative events on attention/concentration were most commonly cited and divided into the following three

Table 1. Number and Percentage of Participants Who Identified Adverse Events in Each Group by Domain

\begin{tabular}{lcccc}
\hline & $\begin{array}{c}\text { Participants } \\
\text { with ADHD } \\
\text { N (12), } \\
(\%)\end{array}$ & Parents & $\begin{array}{c}\text { Clinicians } \\
\text { N (15), } \\
(\%)\end{array}$ & $\begin{array}{c}\text { Teachers } \\
\text { N (10), } \\
(\%)\end{array}$ \\
\hline Cognition & $11(92)$ & $5(62)$ & $13(87)$ & $9(90)$ \\
Motivation & $9(75)$ & $4(50)$ & $7(47)$ & $6(60)$ \\
Mood & $9(75)$ & $5(62)$ & $12(80)$ & $8(80)$ \\
\hline
\end{tabular}

ADHD, attention-deficit/hyperactivity disorder.
Table 2. Summary of Domains

\begin{tabular}{|c|c|}
\hline Category & Domain \\
\hline \multirow[t]{7}{*}{ Cognitive } & Slower attention/concentration \\
\hline & Changes in thinking \\
\hline & Reduced creativity \\
\hline & Sensory overload \\
\hline & Poorer memory \\
\hline & Slower processing speed \\
\hline & Dampening of mood/spontaneity \\
\hline \multirow[t]{3}{*}{ Mood } & Mood dysregulation \\
\hline & Sense of being different \\
\hline & Increased anxiety \\
\hline \multirow[t]{4}{*}{ Motivation } & $\begin{array}{l}\text { Loss of intrinsic motivation for goal-directed } \\
\text { activities }\end{array}$ \\
\hline & External locus of control \\
\hline & Lack of effort/engagement in daily tasks \\
\hline & Increased focus on rewards/incentives \\
\hline
\end{tabular}

subdomains: (i) zoning out/staring leading patients to experience a lack of clarity of thought and tendency to stare into space for long periods of time, (ii) hyper- or over-focusing particularly leading to difficulties transitioning or dividing attention between tasks, and (iii) increased distractibility. (2) Undesirable changes in thinking patterns were the second most frequently mentioned domain of cognitive adverse events with MPH treatment, and it included two subdomains; (i) increased fixation on one's thoughts, which included the single-minded absorption in one's thoughts and/or preoccupation with doing things in a certain predetermined way and (ii) rigid thinking led users to struggle to consider another's point of view or alternative ways of doing things.

(3) Reduced creativity was reported by individuals who described a sensation of overly structured thinking experienced at the expense of creativity. (4) The fourth cognitive domain involved sensory overload. Here, respondents reported that their senses were heightened often to an undesirable degree after taking MPH. This led to a hyperawareness of surroundings, which was perceived as negative and ultimately impacted on thinking, when experienced acutely. (5) Poorer memory was reported by $18 \%$ of participants. In particular, individuals described increased forgetfulness and trouble remembering or recalling recent events. (6) The sixth and final cognitive domain mentioned was slower processing speed; some participants talked about responding to events more slowly, which led to a dampening of their competitive drive, while others spoke of slower thoughts, which were particularly problematic for those who wished to be creative. Here, analytic depth was perceived to lead to the negative sensation of a reduction in quick thinking and an increase in the time it takes to process information.

Motivation. The motivation category had four domains. (1) First, experiences/events related to loss of intrinsic motivation for goal-directed activities referred to patients taking MPH, who described themselves as more compliant and more able to complete activities, but experiencing less intrinsic motivation. (2) The second domain in relation to motivation was the development of an external locus of control. Participants reported that some individuals with ADHD may attribute behavior regulation to medication rather than to their own ability. (3) Some individuals reported MPH led to a lack of effort/engagement with tasks, for example, MPH was perceived to lead to increased difficulties initiating or participating in everyday tasks such as tidying or homework. (4) Finally, some 
participants noted that MPH users were more demanding of and required increased focus on rewards/incentives to complete tasks on medication. They also reported that medication led to a greater expectation and need for others to praise or reward them for activities.

Mood. A third domain, described as mood-related, emerged as the second most frequently cited adverse event of MPH. There were three subdomains. (1) The most commonly cited being dampening of spontaneity. This included descriptions of individuals losing their spark and becoming dull or boring when medicated. (2) The second most frequently described mood-related adverse event was related to mood dysregulation. Mood swings, emotional lability, and feelings of depression were reported. Secondary repercussions of this involved individuals being unable to think about and focus on tasks given their experience of negative affect. (3) Events related to increased anxiety while on medication were also mentioned. Here, participants gave the example of subjects choosing not to take MPH on days likely to be stressful (e.g., test days or important meetings) as they felt it would amplify and worsen anxiety.

Initial development of the prototype Medication and Cognition Questionnaire. All of the domains and subdomains described in the coding manual and listed in Table 3 were used to develop prototypical questionnaire items for the Medication and Cognition Questionnaire (MCQ). Two items per domain/subdomain were created. Where possible, these were paraphrased from participants' own words (Table 4).

The first draft of the questionnaire was piloted with 20 children with ADHD, aged 7-16 years (mean $=11.2$; $\mathrm{SD}=2.69)$ participating in the ADDUCE project (www.adhd-adduce.org), who had been taking MPH for 18 months. Following this pilot phase, it was found that 20/34 items were not consistently understood by some of the younger participants. A focus group of six typically developing children aged 7 years, who did not have diagnosis of ADHD, was formed to help generate age-appropriate phrasing for these items. For example, the item "Had difficulty considering alternative ways of doing things" was changed to "had trouble thinking of different ways to do things (like when doing a maths problem)". The final item set is listed in Table 4.

The final questionnaire is being piloted within the larger ADDUCE project trial at the 18-month data collection point across the four European sites (United Kingdom, Hungary, Italy, and Germany). These data will then be used to investigate the internal consistency and factor loading of the items, and to further refine the items as necessary, for example, to ensure they are developmentally appropriate and understandable across a wide age range. We will also assess the psychometric properties of the MCQ, including conducting test-retest reliability with a subset of participants, and through tests of concurrent (e.g., looking at the relationship with mood measures) and predictive validity (looking at outcomes and medication adherence across the sample).

\section{Discussion}

Our interviews with our purposively selected and nonrepresentative sample of clinicians, teachers, parents, and individuals with ADHD about their negative experiences and reports of MPH use, provided descriptions of potential adverse events of MPH on cognition, motivation, and mood, at least in most cases. The purpose of our qualitative interview was to harvest an in-depth and broad account of any potential cognitive or functional impact (regardless of dose), in a sample of participants enriched for experi- ence/knowledge of adverse events/reactions to MPH. That is to say, participants all had direct (as in the case of patients) or indirect experience of adverse events/reactions more generally.

Crucially, this was not a survey of adverse events associated with MPH in a representative sample of MPH-treated ADHD patients, and so, proportions of individuals reporting events cannot in any way be equated with prevalence rates, for example, from controlled clinical trials or postmarket reporting. Determination of prevalence rates of these adverse events is currently being undertaken with the MCQ as part of the ADDUCE 2-year longitudinal naturalistic prospective pharmacovigilance study (Inglis et al. submitted) and will be reported separately.

With these caveats in mind, our findings corroborate and extend the conclusions of an emergent body of literature that has sought to examine possible adverse impacts of stimulant medication from patient and practitioner perspectives. Accordingly, Charach et al. (2014) conducted qualitative interviews with 12 young people aged 12-15 years and their parents to investigate their attitudes toward use of stimulant medication. While most participants noted the benefits of stimulants in multiple domains, they also expressed concerns about negative changes in their subjective experience and feelings about themselves. They reported that their medication caused them to feel less happy, quieter, weird, unsociable, and less outgoing. They also noted other adverse events, including headaches and mood lability, which alongside the undesirable changes in their sense of self led to a desire to discontinue medication.

Similarly, Meaux et al. (2006, p. 220) interviewed 15 college students with ADHD about their experience of stimulant medication. While all participants agreed that stimulants improved their concentration and focus, many also recounted that taking stimulants involved a trade-off between any benefits of the medication and undesirable cognitive, behavioral, social, and physiological effects of the drug. In particular, they described feeling like everything was in slow motion, their daily experiences involved feeling flat or monotone, and that the medication made them feel unsociable and killed their personality.

As part of the ADHD VOICES Study, Singh et al. (2010) conducted focus groups and 1:1 interviews with 16 young people with ADHD on medication to gather information about their experiences of stimulant treatment. Generally, the participants in their study did not report any specific adverse events of stimulant medication. However, in their final report of this study, Singh (2012, p. 24) acknowledges that a "small group of children" felt that stimulant medication "gave them a "second personality.",

When taking into account the perspectives of not only patients with ADHD but also parents, experienced clinicians, and teachers, the participants in our study identified adverse events that they perceived to be associated with MPH treatment and related to or associated with cognition, motivational style, and mood. Interestingly, participants in the current study also reported that individuals with MPH treatment developed strategies to manage any unwanted effects of the medication. For example, those who believed that MPH exacerbated their anxiety would avoid taking their medication on days in which they were worried the impact of the medication might impede performance. However, failure to take prescribed medication may have other important costs to the individual where enhanced attention and concentration are required. Others were able to manage their medication use so that they chose when was most suitable for them to take their medication. For example, those who were required to be risk-taking or creative as part of their jobs or sporting activities avoided taking the medication for key events, and took it only when they felt it would be 
TABLE 3. MCQ ITEMS

\begin{tabular}{|c|c|c|c|c|c|c|c|}
\hline \multirow{2}{*}{$\frac{\text { Over the last } 4 \text { weeks have you ... }}{1 . \text { Over-focused on jobs you had to do }}$} & \multirow{2}{*}{$\begin{array}{c}\text { Not } \\
\text { at all } \\
0\end{array}$} & \multirow{2}{*}{$\begin{array}{c}\begin{array}{c}A \\
\text { little }\end{array} \\
1\end{array}$} & \multirow{2}{*}{$\begin{array}{c}\begin{array}{c}\text { More } \\
\text { or less }\end{array} \\
2\end{array}$} & \multirow{2}{*}{ A lot } & \multirow{2}{*}{$\frac{\text { Completely }}{4}$} & \multicolumn{2}{|c|}{$\begin{array}{l}\text { Is this a problem } \\
\quad \text { for you? }\end{array}$} \\
\hline & & & & & & Yes & No \\
\hline 2. Had trouble remembering recent experiences or events & 0 & 1 & 2 & 3 & 4 & Yes & No \\
\hline $\begin{array}{l}\text { 3. Had trouble thinking of different ways to do things (e.g., like } \\
\text { when you are doing a maths problem) }\end{array}$ & 0 & 1 & 2 & 3 & 4 & Yes & No \\
\hline 4. Felt like you weren't putting much effort into things & 0 & 1 & 2 & 3 & 4 & Yes & No \\
\hline 5. Been anxious or worried & 0 & 1 & 2 & 3 & 4 & Yes & No \\
\hline 6. Not been interested or excited to achieve your goals & 0 & 1 & 2 & 3 & 4 & Yes & No \\
\hline 7. Been distracted & 0 & 1 & 2 & 3 & 4 & Yes & No \\
\hline 8. Expected or wanted other people to praise or reward you & 0 & 1 & 2 & 3 & 4 & Yes & No \\
\hline 9. Been emotional (e.g., had lots of strong feelings) & 0 & 1 & 2 & 3 & 4 & Yes & No \\
\hline 10. Felt more boring and less exciting than usual & 0 & 1 & 2 & 3 & 4 & Yes & No \\
\hline 11. Had a very sensitive sense of smell, touch, taste or hearing & 0 & 1 & 2 & 3 & 4 & Yes & No \\
\hline 12. Been thinking slowly & 0 & 1 & 2 & 3 & 4 & Yes & No \\
\hline 13. Been well behaved & 0 & 1 & 2 & 3 & 4 & Yes & No \\
\hline 14. Noticed your thinking was fuzzy or confused & 0 & 1 & 2 & 3 & 4 & Yes & No \\
\hline 15. Felt nervous or had butterflies in your stomach & 0 & 1 & 2 & 3 & 4 & Yes & No \\
\hline 16. Not been creative & 0 & 1 & 2 & 3 & 4 & Yes & No \\
\hline 17. Noticed your mood or temper kept changing & 0 & 1 & 2 & 3 & 4 & Yes & No \\
\hline 18. Been sensitive to sights, sounds, or touch & 0 & 1 & 2 & 3 & 4 & Yes & No \\
\hline 19. Been focused on doing things in a certain way & 0 & 1 & 2 & 3 & 4 & Yes & No \\
\hline 20. Been forgetful & 0 & 1 & 2 & 3 & 4 & Yes & No \\
\hline $\begin{array}{l}\text { 21. Not been pushing yourself to work as hard or harder than } \\
\text { other people }\end{array}$ & 0 & 1 & 2 & 3 & 4 & Yes & No \\
\hline 22. Needed and wanted to be rewarded for work/behaviour & 0 & 1 & 2 & 3 & 4 & Yes & No \\
\hline $\begin{array}{l}\text { 23. Been focused on your own thoughts (e.g., can't get out } \\
\text { of your head) }\end{array}$ & 0 & 1 & 2 & 3 & 4 & Yes & No \\
\hline 24. Not shown creativity & 0 & 1 & 2 & 3 & 4 & Yes & No \\
\hline $\begin{array}{l}\text { 25. Had trouble trying to understand other people's views } \\
\text { or opinions }\end{array}$ & 0 & 1 & 2 & 3 & 4 & Yes & No \\
\hline 26. Had slow reflexes or reacted slowly & 0 & 1 & 2 & 3 & 4 & Yes & No \\
\hline 27. Found it difficult to think quickly & 0 & 1 & 2 & 3 & 4 & Yes & No \\
\hline $\begin{array}{l}\text { 28. Found it really hard to start your normal everyday tasks } \\
\text { (e.g., morning work or household chores) }\end{array}$ & 0 & 1 & 2 & 3 & 4 & Yes & No \\
\hline 29. Been "good" & 0 & 1 & 2 & 3 & 4 & Yes & No \\
\hline 30. Thought too hard or were lost in your own thoughts & 0 & 1 & 2 & 3 & 4 & Yes & No \\
\hline 31. Stared at things or people & 0 & 1 & 2 & 3 & 4 & Yes & No \\
\hline 32. Had no personality or "get-up-and-go" & 0 & 1 & 2 & 3 & 4 & Yes & No \\
\hline 33. Not been making an effort & 0 & 1 & 2 & 3 & 4 & Yes & No \\
\hline 34. Had trouble concentrating & 0 & 1 & 2 & 3 & 4 & Yes & No \\
\hline
\end{tabular}

MCQ, Medication and Cognition Questionnaire.

desirable to slow down thinking, and some of our participants only took it for tasks where creativity was not required.

Still others expressed uncertainty about whether the adverse events they experienced could be directly attributed to the medication or to other causes such as puberty or comorbid mental illnesses, or simply to a greater understanding or awareness of their ADHD symptoms.

\section{Limitations}

While the participants in this study have introduced several interesting avenues for future research and consideration, it is important to note the caveats with which these data must be interpreted. This research represents a specific and goal-oriented exercise in gathering examples of adverse events associated with MPH treatment. For this purpose, a comparison group of individuals who did not experience negative effects of MPH were not required as the ultimate goal was to collate only the adverse events described during our interview study to develop a measure of adverse events related to/associated with
$\mathrm{MPH}$. This measure will now require testing in large, representative samples of ADHD patients both on and off MPH medication, with and without a positive adverse effect profile, to control for bias effects. Additional testing and refinement may also be required to ensure that the measure has good validity and developmental sensitivity for both younger children and adult populations. Without this test of the data, the adverse events reported here cannot and should not be directly attributed to MPH.

\section{Conclusions}

Management and identification of these sorts of adverse events require further attention and a more systematic and standardized approach to disentangle some of the issues raised. Moreover, further systematic study of these possible adverse events is also important to clarify their relationship with predictive/moderating variables (e.g., comorbid conditions, personality traits, genetic variance, and potential relationships with physiological side effects). It would also be of clinical importance to identify which 
Table 4. Detailed Information About Each Domain and Subdomain in Order of Frequency (\%) of Reporting

\begin{tabular}{|c|c|c|c|c|}
\hline Dom & Subdomain & $\begin{array}{l}\mathrm{N}(\%) \text { of } \\
\text { participants } \\
\text { reporting }\end{array}$ & Statement & Detailed illustrative quote \\
\hline \multirow[t]{2}{*}{ Mood } & $\begin{array}{l}\text { Dampening of mood/ } \\
\text { spontaneity }\end{array}$ & $31(69 \%)$ & $\begin{array}{r}\text { Feel like I'd } \\
\text { lost spark }\end{array}$ & $\begin{array}{l}\text { Actually some of the teenage boys complain that they are not } \\
\text { interesting when they are on MPH, they'll say "I am really } \\
\text { chatty and girls like me when I am not on my MPH, and when } \\
\text { I take it yes I get more work done but I am too quiet, I am dull } \\
\text { and I don't like it." I've had a couple that asked to be taken } \\
\text { off it because girls find them boring (C1) }\end{array}$ \\
\hline & & & Personality dull & $\begin{array}{l}\text { I have an ADHD and that is the only way I know of myself, } \\
\text { that's how I know I am being me, like you know you are } \\
\text { being you, and when I take meds I feel different which is } \\
\text { why I don't like to think of it. With ADHD I feel like quite } \\
\text { an exceptional person and when I am off my meds I can } \\
\text { think of things creatively and people -when they see me off } \\
\text { my medication they know it's me. When I am on my meds } \\
\text { [...] my personality, me is shut off (AC2) }\end{array}$ \\
\hline \multirow[t]{2}{*}{ Mood } & Mood dysregulation & $21(47 \%)$ & Emotional & $\begin{array}{l}\text { I did cry more when I was on medication I think I was so tired, } \\
\text { I was tired and frustrated that I was tired so I got bit } \\
\text { emotional about things probably a week or so after I started } \\
\text { taking it (AC2) }\end{array}$ \\
\hline & & & Mood swings & $\begin{array}{l}\text { We have seen changes in mood, unexplained crying, scream- } \\
\text { ing, agitation, even on small doses of methylphenidate (C9) }\end{array}$ \\
\hline \multirow[t]{2}{*}{$\operatorname{Cog}$} & $\begin{array}{l}\text { Attention/concentra- } \\
\text { tion (zoning out/ } \\
\text { staring) }\end{array}$ & $21(47 \%)$ & $\begin{array}{l}\text { Thoughts foggy } \\
\text { or spacey }\end{array}$ & $\begin{array}{l}\text { It's like you've been asleep and you just woke up and your } \\
\text { head is all foggy. It's like that it puts you in that sort of } \\
\text { mode ... in a way like you smoked too many spliffs ... so } \\
\text { it's ... fogs your head. it's like you just feel like a zombie. } \\
\text { there's much you can physically do, things that are in front } \\
\text { of you. I was off my head "oh what's going on with my } \\
\text { concentration" (AC4) }\end{array}$ \\
\hline & & & $\begin{array}{l}\text { Stare at things for } \\
\text { long periods }\end{array}$ & $\begin{array}{l}\text { In some cases not only staring for a long period but they look } \\
\text { really withdrawn and non-reactive on very rare occasion } \\
\text { (C3) }\end{array}$ \\
\hline \multirow[t]{2}{*}{ Mot } & $\begin{array}{l}\text { Loss of intrinsic } \\
\text { motivation }\end{array}$ & $16(36 \%)$ & $\begin{array}{l}\text { Less motivated to } \\
\text { achieve goals }\end{array}$ & $\begin{array}{l}\text { I think I can attain something when I am on it, but the desire to } \\
\text { attain it is greater when I am off it [...] I find it easier to } \\
\text { attain a goal when on meds but to be honest I am personally } \\
\text { not that bothered about it then (AC3) }\end{array}$ \\
\hline & & & $\begin{array}{l}\text { Less motivated } \\
\text { than usual }\end{array}$ & $\begin{array}{l}\text { They sit down in a desk writing in a book, holding a pen, listen } \\
\text { to a teacher, describe what they are going to do is much } \\
\text { easier when they are medicated because they are not...it } \\
\text { sounds awful, but they are not necessarily inspired they } \\
\text { know they just need to sit down and do it if that makes sense } \\
\text { (T2) }\end{array}$ \\
\hline \multirow[t]{2}{*}{$\operatorname{Cog}$} & $\begin{array}{l}\text { Changes in thinking } \\
\text { (Increased fixation } \\
\text { on thoughts) }\end{array}$ & $15(33 \%)$ & $\begin{array}{l}\text { Preoccupied by } \\
\text { doing things in } \\
\text { certain way }\end{array}$ & $\begin{array}{l}\text { We have children who did a lot of...more collecting [things] } \\
\text { and sorting and ordering. And we had children who had pre- } \\
\text { occupation with thought -you know, repeating obsessional } \\
\text { thoughts (C9) }\end{array}$ \\
\hline & & & $\begin{array}{l}\text { Fixated with own } \\
\text { thoughts }\end{array}$ & $\begin{array}{l}\text { When you think... you feel like you think over and too much } \\
\text { on it... (AC4) }\end{array}$ \\
\hline \multirow[t]{2}{*}{$\operatorname{Cog}$} & Reduced creativity & $13(29 \%)$ & Less creative & $\begin{array}{l}\text { If I've been shooting a film we've got lots of stuff going on and } \\
\text { it's the kind of film that I know how to make very well, you } \\
\text { know, the kind of thing we do a lot, then I won't take the } \\
\text { drugs at all. And while we're doing all the editing and post } \\
\text { production I generally won't take the drugs either because } \\
\text { the drugs are very, very good if you've got to do loads of } \\
\text { different meetings with clients and things like that, but they } \\
\text { are not that great if you want to think very creatively (AC5) }\end{array}$ \\
\hline & & & Overly logical & $\begin{array}{l}\text { I am not as creative with my thinking as I am without it } \\
\text { [...]When I am off my medication, I can be quite creative } \\
\text { especially solving things and looking at things in different } \\
\text { ways and when I am on medication it's harder to do that; I } \\
\text { get quite logical and I come to that point where I am too } \\
\text { logical (AC3) }\end{array}$ \\
\hline
\end{tabular}


TABle 4. (Continued)

\begin{tabular}{|c|c|c|c|c|}
\hline Dom & Subdomain & $\begin{array}{l}\mathrm{N}(\%) \text { of } \\
\text { participants } \\
\text { reporting }\end{array}$ & Statement & Detailed illustrative quote \\
\hline \multirow[t]{2}{*}{$\operatorname{Cog}$} & Sensory overload & $13(29 \%)$ & $\begin{array}{l}\text { Senses } \\
\quad \text { overpowering }\end{array}$ & $\begin{array}{l}\text { Sometimes he is saying when you are not even shouting or not } \\
\text { shouting very loudly, he'll say you are shouting at him. So I } \\
\text { don't know, it may have an impact there. He says "you are } \\
\text { shouting, shouting all the time" and yet he'll be shouting. He'll } \\
\text { shout when he wants to. It's okay for him to do that but he } \\
\text { doesn't like anyone to raise their voice (P5) }\end{array}$ \\
\hline & & & $\begin{array}{l}\text { Hypersensitive } \\
\text { to sight/sound/ } \\
\text { taste }\end{array}$ & $\begin{array}{l}\text { Yeah your touch and your smell and everything else is more } \\
\text { heightened, the taste buds ... It messes up all your senses } \\
\text { really. The colours are more brighter. Yeah things are more } \\
\text { brighter... kinda strange (AC2) }\end{array}$ \\
\hline \multirow[t]{2}{*}{$\operatorname{Cog}$} & $\begin{array}{l}\text { Attention/concentra- } \\
\text { tion (hyperfocusing } \\
\text { on tasks) }\end{array}$ & $12(27 \%)$ & $\begin{array}{l}\text { Focus too much } \\
\text { on tasks }\end{array}$ & $\begin{array}{l}\text { My husband had to deal with everything cos I couldn't put my } \\
\text { attention on all sorts of different things that I normally } \\
\text { would do. Normally I got all } 4 \text { [children] of them spinning } \\
\text { around me and now I deal with it to some degree, but on } \\
\text { meds I wasn't dealing with it at all. Just didn't wanna know } \\
\text { [...] I'd spend } 15 \text { hours putting together a presentation for } \\
\text { my MD (AC2) }\end{array}$ \\
\hline & & & $\begin{array}{l}\text { Over-focus } \\
\text { on jobs }\end{array}$ & $\begin{array}{l}\text { I'll just sit there and do what I enjoy and get really fixed on } \\
\text { that, much more than I would normally do without my } \\
\text { medication. Things like eating, washing up, I seem to focus } \\
\text { a lot more on them than I would without my medication } \\
\text { (AC3). }\end{array}$ \\
\hline \multirow[t]{2}{*}{ Mood } & Increased anxiety & $9(20 \%)$ & Anxious & $\begin{array}{l}\text { There's this inner nag, it makes me feel like I am wasting my } \\
\text { time but I also feel like I can't ... Like I don't want to stop. I } \\
\text { feel like there is some anxious feeling (AC6) }\end{array}$ \\
\hline & & & Feel on edge & $\begin{array}{l}\text { I can get more anxious at times. I have good days and bad } \\
\text { days. I think I suffer with anxiety anyway but there are days } \\
\text { when I think "I'm not going to take one today" because I } \\
\text { just know it will make me slightly worse. So if I'm having a } \\
\text { really off day then I would leave it because I know that it } \\
\text { can have an effect on anxiety (AC8) }\end{array}$ \\
\hline \multirow[t]{2}{*}{$\operatorname{Cog}$} & Memory & $8(18 \%)$ & Forgetful & $\begin{array}{l}\text { Yes, I think he has probably got more forgetful. I have to tell } \\
\text { him more than once to do something... more like five times } \\
\text { sometimes... (P2) }\end{array}$ \\
\hline & & & $\begin{array}{l}\text { Trouble } \\
\text { remembering } \\
\text { recent events }\end{array}$ & $\begin{array}{l}\text { I will forget things all the time... I forget where my shoes are, I } \\
\text { forgot what lessons I need to go to on the day, what time it is } \\
\text { (AC1) }\end{array}$ \\
\hline \multirow[t]{2}{*}{$\operatorname{Cog}$} & $\begin{array}{l}\text { Slower processing } \\
\text { speed (MPH slow } \\
\text { reaction time) }\end{array}$ & $7(16 \%)$ & $\begin{array}{l}\text { Loss of } \\
\text { competitive } \\
\text { edge }\end{array}$ & $\begin{array}{l}\text { I have had a couple of young people, one of them was sporting } \\
\text { champion who didn't take Ritalin before competition } \\
\text { because he felt it just dampened his competitive edge and } \\
\text { that he needed to be more "devil may care" to be able to } \\
\text { compete C2) }\end{array}$ \\
\hline & & & $\begin{array}{l}\text { Became slower } \\
\text { to react }\end{array}$ & $\begin{array}{l}\text { I find my reactions are a lot slower on tablets then off tablets. I } \\
\text { do kickboxing and I find it very hard to do the quick fighting } \\
\text { on tablets that I do off tablets[...] For your reactions to be } \\
\text { quick it has to be a natural thing that you do. Off a tablet I } \\
\text { see everything I see all the little things I hear all the little } \\
\text { things I am really supersensitive. On a tablet it dims it all } \\
\text { down, it puts a blanket over everything (AC4) }\end{array}$ \\
\hline Mot & $\begin{array}{l}\text { External locus of } \\
\text { control (being good } \\
\text { attributed to } \\
\text { medication) }\end{array}$ & $7(16 \%)$ & Became good & $\begin{array}{l}\text { Interestingly you sometimes get children who will say things } \\
\text { like "oh I haven't had my tablet today so I am not going to } \\
\text { be good" or "I can't be good today cos I haven't had my } \\
\text { tablet" which obviously sounds rather horrifying to us. } \\
\text { Either they got that message from school or home or perhaps } \\
\text { they have come up with it themselves where they believe } \\
\text { they are only good because they are taking the tablet[...] I } \\
\text { give them MPH and they get the message that they are only } \\
\text { good and only acceptable and only likeable because they are } \\
\text { on MPH which is pretty horrific (C1) }\end{array}$ \\
\hline
\end{tabular}


TABLE 4. (CONTINUED)

\begin{tabular}{|c|c|c|c|c|}
\hline Dom & Subdomain & $\begin{array}{l}\mathrm{N}(\%) \text { of } \\
\text { participants } \\
\text { reporting }\end{array}$ & Statement & Detailed illustrative quote \\
\hline & & & Well behaved & $\begin{array}{l}\text { They sort of come in and said "I am so much happier now I'm } \\
\text { a good boy everyone likes me" but }[\ldots] \text { are they just more } \\
\text { compliant with people or is there a fundamental shift in } \\
\text { cognition (C2) }\end{array}$ \\
\hline \multirow[t]{2}{*}{$\operatorname{Cog}$} & $\begin{array}{l}\text { Changes in thinking } \\
\text { (increased rigidity } \\
\text { of thought) }\end{array}$ & $7(16 \%)$ & $\begin{array}{l}\text { Trouble } \\
\text { considering } \\
\text { others' } \\
\text { viewpoints }\end{array}$ & $\begin{array}{l}\text { No...not able to take it in, other people's point of view. I was } \\
\text { trying to listen to people, I was asking people for advice [...] } \\
\text { but now I think it's more because I thought my decision was } \\
\text { right...like if they'd say "I think you should do this" I'd be } \\
\text { like "Well actually no I think we should do that" (AC2) }\end{array}$ \\
\hline & & & $\begin{array}{l}\text { Unable to consider } \\
\text { different ways } \\
\text { of doing things }\end{array}$ & $\begin{array}{l}\text { There is less negotiating and they do have very strong ideas } \\
\text { that can't be changed }[\ldots] \text { Those that are on it }[\mathrm{MPH}] \text { do } \\
\text { seem to be the ones that do have the more sort of } \\
\text { unwavering ideas (T3) }\end{array}$ \\
\hline \multirow[t]{2}{*}{ Mot } & $\begin{array}{c}\text { Lack of effort/engage- } \\
\text { ment in daily tasks }\end{array}$ & $7(16 \%)$ & $\begin{array}{l}\text { Difficult to start } \\
\text { routine or daily } \\
\text { tasks }\end{array}$ & $\begin{array}{l}\text { Everyday tasks are more hard to get motivated about to start on } \\
\text { my medication than without. I find them easier to do without } \\
\text { MPH. I find it easier to finish them but I can't start them. I: } \\
\text { What tasks do you find harder to start? AC3::just everyday } \\
\text { tasks that I find boring, like tidying up, cleaning up, things } \\
\text { that I have no interest in [...]I've got to plan to do hard stuff } \\
\text { when I am off my medication cos it's easier to start (AC3) }\end{array}$ \\
\hline & & & $\begin{array}{l}\text { Put less effort into } \\
\text { things }\end{array}$ & $\begin{array}{l}\text { Things like going to the toilet. Lad in my class, when he is } \\
\text { medicated we have to remind him to do things like that. } \\
\text { Which is really strange, you have to say "it's break time, } \\
\text { you need to go to the toilet, its lunch time you need to go to } \\
\text { the toilet, it's home time, you need to go to the toilet." It's } \\
\text { not something I would have to do if he wasn't medicated } \\
\text { (T2) }\end{array}$ \\
\hline \multirow[t]{2}{*}{$\operatorname{Cog}$} & $\begin{array}{l}\text { Processing speed } \\
\quad \text { (slower thinking) }\end{array}$ & $6(13 \%)$ & $\begin{array}{l}\text { Difficult to think } \\
\text { quickly }\end{array}$ & $\begin{array}{l}\text { What the young person is saying is that I don't want to have } \\
\text { that boring, detailed ... I don't want to have the analytical } \\
\text { depth; I want to have the free-thinking, whizzy brain stuff, } \\
\text { which is ideal for entrepreneurial thinking (C13) }\end{array}$ \\
\hline & & & $\begin{array}{l}\text { Thinking more } \\
\text { slowly than } \\
\text { usual }\end{array}$ & $\begin{array}{l}\text { It's like they are sitting in honey, it becomes such a tedious, } \\
\text { slow process for them and you know that they would've got } \\
\text { yesterday in an instant, takes a really long time for them to } \\
\text { process that information. I find that if they are that way out, } \\
\text { they don't retain their information at all. If they are at a } \\
\text { point where they are just repressed by that drug, they don't } \\
\text { retain the information that they've just learnt (T2) }\end{array}$ \\
\hline \multirow[t]{2}{*}{ Mot } & $\begin{array}{l}\text { Increased focus on } \\
\text { rewards/incentives/ } \\
\text { external praise }\end{array}$ & $6(13 \%)$ & $\begin{array}{l}\text { Need to be } \\
\text { rewarded for } \\
\text { doing work }\end{array}$ & $\begin{array}{l}\text { Q1: If he's like "If I do this dad or do this mum will I get that } \\
\text { at the end of the week?" and you say "Yeah," so he thinks a } \\
\text { lot about rewards. Interviewer: and was he like that before } \\
\text { Ritalin? P1: Not as much (P1) }\end{array}$ \\
\hline & & & $\begin{array}{l}\text { Expect others to } \\
\text { praise or } \\
\text { reward me }\end{array}$ & $\begin{array}{l}\text { For example, if they join a reading group, we have got the } \\
\text { treasure chest out to choose a present once they have } \\
\text { achieved a certain level of reading or whatever, but they } \\
\text { seem to be quite needy and ask right from the beginning } \\
\text { "what will my prize be?" So it seems to be a longing to } \\
\text { already know what is going to happen, what the outcome is } \\
\text { going to be (T5) }\end{array}$ \\
\hline \multirow[t]{2}{*}{$\operatorname{Cog}$} & $\begin{array}{l}\text { Attention/concentra- } \\
\text { tion (increased dis- } \\
\text { traction) }\end{array}$ & $5(11 \%)$ & Distracted & $\begin{array}{l}\text { Basically I think normally what might happen is I'll be doing } \\
\text { something complex and another thought will come into my } \\
\text { head and it might be something like ... oh how long have I } \\
\text { got to do this left? It might be something related to the task, } \\
\text { but something will come in and that will distract you just } \\
\text { enough to let you forget it (AC6) }\end{array}$ \\
\hline & & & $\begin{array}{l}\text { Trouble } \\
\text { concentrating }\end{array}$ & $\begin{array}{l}\text { There are ones who have said they can't concentrate, they can't } \\
\text { pay attention[to a task] (C7) }\end{array}$ \\
\hline
\end{tabular}

AC, adult/child with ADHD; ADHD, attention-deficit/hyperactivity disorder; C, clinician; Cog, cognitive; I, Interviewer; Mot, motivation; P, parent, T, teacher; number, participant number (e.g., P1, parent 1). 
children are most likely to develop adverse cognitive, motivational, or mood-related adverse events (e.g., with co-occurring anxiety symptoms).

\section{Clinical Significance}

The limitations above notwithstanding our tentative findings extend some of the recent reports of adverse events of MPH in the literature by specifically addressing the putative negative impact of MPH treatment on the specific domains of cognitive, motivational, and mood functioning with a broader range of participant groups. Despite the more common experience of positive effects of MPH therapy, for some individuals at least, the perceived negative impact of MPH use on their thinking, mood, and motivation has potential implications for treatment. Many clinicians interviewed in this study noted that they did not routinely screen for these types of adverse events and only recorded them if the patient spontaneously reported them. Accordingly, the use of a standardized tool to gather information about cognitive, motivational, and mood effects of MPH in clinical practice may help to focus psychoeducational approaches on respective findings and, thus, hopefully contribute to medication adherence and treatment alliance (Adler and Nierenberg 2010). Moreover, a greater understanding of the potential adverse events of medication on these important, but often overlooked, areas will ultimately improve individualized patient care.

\section{Acknowledgments}

The authors thank all of the participants who shared their experiences with MPH treatment with the researchers. This project has received funding from the European Union's Seventh Framework Programme for research, technological development, and demonstration under grant agreement no. 324487.

\section{Disclosures}

In the last 3 years, E.J.S.S.-B.--fees for speaking, consultancy, research funding, and conference support from Shire Pharma. Speaker fees from Janssen Cilag, Medice \& Qbtech. Book royalties from OUP and Jessica Kingsley. Consultancy from Neurotech solutions.

In the last 3 years, D.C. served in an advisory or consultancy role for Flynn Pharma, Lilly, Novartis, Shire and Vifor Pharma. He received speaker's fee from Lilly, Novartis, and Shire. He is/has been involved in research sponsored by Shire and Vifor Pharma. He has received royalties from Oxford University Press. The present work is unrelated to the above grants and relationships.

I.C.K.W. received funding from the EU FP7 grant, Hong Kong Research Grant Council, and Janssen Cilag for ADHD research.

R.W.D. is a former employee of Eli Lilly \& Co. and owner of Lilly stock. He has served in an advisory or consultancy role for Boehringer Ingelheim, Janssen-Cilag, Lilly, Lundbeck, Servier, and Shire. He has received conference attendance support and received speaker's fees from Boehringer Ingelheim, Lilly, and Shire. $\mathrm{He}$ has been involved in clinical trials conducted by Ferring, Janssen-Cilag, Lilly, Otsuka, Shire, and Sunovion. He has received research funding from the US National Institute of Mental Health (NIMH), the European Union (EU FP7), the German Research Foundation (DFG), the German Ministries of Research and Education (BMBF) and Health (BMG/BfArM), and the Volkswagen Foundation

J.K.B. has been in the past 3 years a consultant to/member of advisory board of/and/or speaker for Janssen Cilag BV, Eli Lilly, and Servier. He is not an employee of any of these companies and not a stock shareholder of any of these companies. He has no other financial or material support, including expert testimony, patents, and royalties. He has received research funding from the US National Institute of Mental Health (NIMH), the European Union (EU FP7, Horizon2020, and Innovative Medicines Initiative schemes), the Netherlands Organization for Scientific Research (NWO), and Zorgonderzoek Nederland (ZonMW).

T.B. served in an advisory or consultancy role for Hexal Pharma, Lilly, Medice, Novartis, Otsuka, Oxford outcomes, PCM scientific, Shire and Vifor Pharma. He received conference attendance support and conference support or received speaker's fee by Lilly, Medice, Novartis, and Shire. He is/has been involved in clinical trials conducted by Shire and Vifor Pharma. The present work is unrelated to the above grants and relationships.

S.C. within the last 3 years received conference attendance support by Shire. She has been involved in clinical trials conducted by Shire. She is participating in EU FP7 funded project.

S.M. has in the past 3 years received conference attendance and research support from Shire. She has received funding from the European Union (EU FP7).

M.D. has received research support from Janssen-Cilag and Shire and has been a consultant to/member of advisory board of/and/or speaker for Shire, Novartis, Medice, and Neurotech Solutions. She is not an employee or stock shareholder of any of these companies.

A.Z. has been in the last 3 years a consultant to/member of advisory board of/and/or speaker for Shire, Eli Lilly, Vifor, Otsuka, Lundbeck, and Takeda. He is not an employee of any of these companies and not a stock shareholder of any of these companies. $\mathrm{He}$ has received research funding from the European Union (EU FP7) and the Sardinian Regional Health Secretary and royalties by Oxford University Press and Giunti OS.

K.K. has received speaking fees from Lilly, Novartis, Medice, and Shire. She got an investigator-initiated trial (IIT) by Vivor AG on the effects of polyunsaturated fatty acids on brain maturation in children with and without ADHD.

C.H. receives salary support from the National Institute of Health Research (NIHR) MindTech Healthcare Technology Cooperative.

S.I. is funded by the EU FP7 programme.

\section{References}

Adler LD, Nierenberg AA: Review of medication adherence in children and adults with ADHD. Postgrad Med J 122:184-191, 2010.

Advokat C: What are the cognitive effects of stimulant medications? Emphasis on adults with attention-deficit/hyperactivity disorder (ADHD). Neuroscience Biobehavioural Reviews 34:1256-1266, 2010.

Andersen SL, Napierata L, Brenhouse HC, Sonntag KC: Juvenile methylphenidate modulates reward-related behaviors and cerebral blood flow by decreasing cortical D3 receptors. Eur J Neurosci 27:2962-2972, 2008.

Barkley RA, DuPaul GJ, McMurray MB: A comprehensive evaluation of attention deficit disorder with and without hyperactivity. Journal of Consulting and Clinical Psychology 58:775-789, 1990.

Berridge CW, Devibiss DM, Andrzejewski ME, Arnsten AFT, Kelley AE, Schmeichel B, Hamilton C, Spencer RC: Methylphenidate preferentially increases catecholamine neurotransmission within the prefrontal cortex at low doses that enhance cognitive function. Biol Psychiatry 60:1111-1120, 2006.

Carlson CL, Pelham WE, Milich, R, Hoza, B: ADHD boys' performance and attributions following success and failure: Drug effects and individual differences. Cogn Ther Res 17:269-287, 1993. 
Cortese S, Holtmann M, Banaschewski T, Buitelaar J, Coghill D, Danckaerts M, Dittmann RW, Graham J, Taylor E, Sergeant J, the European ADHD Guidelines Group: Practitioner review: Current best practice in the management of adverse events during treatment with ADHD medications in children and adolescents. J Child Psychol Psychiatry 54:227-246, 2013.

Charach A, Ickowicz A, Schachar R: Stimulant treatment over five years: Adherence, effectiveness, and adverse effects. J Am Acad Child Adolesc Psychiatry 43:559-567, 2004.

Charach A, Yeung E, Volpe T, Goodale T, dosReis S: Exploring stimulant treatment in ADHD: Narratives of young adolescents and their parents. BMC Psychiatry 14:110-110, 2014.

Coghill DR, Seth S, Pedroso S, Usala T, Currie J, Gagliano A: Effects of methylphenidate on cognitive functions in children and adolescents with attention-deficit/hyperactivity disorder: evidence from a systematic review and a meta-analysis. Biological Psychiatry 76: 603-615.

Douglas V, Barr RG, Desilets J, Sherman E: Do high doses of stimulants impair flexible thinking in ADHD? Journal of the Americal Academy of Child and Adolescent Psychiatry 34:877-885, 1995.

European Medicines Agency: Guideline on clinical investigation of medicinal products for the treatment of attentional deficit hyperactivity disorder (adhd), 2010. Available at www.ema.europa.eu/ docs/en_GB/document_library/Scientific_guideline/2010/08/WC 500095686.pdf

Farah MJ, Haimm C, Sankoorikal G, Chatterjee A: When we Enhance Cognition with Adderall, do we Sacrifice Creativity? A Preliminary Study. Psychopharmacology, 2008, pp. 541-547.

Faraone SV, Biederman J, Morley CP, Spencer TJ: Effect of stimulants on height and weight: A review of the literature. J Am Acad Child Adolesc Psychiatry 47:994-1009, 2008.

Faraone SV, Buitelaar J: Comparing the efficacy of stimulants for ADHD in children and adolescents using meta-analysis. Eur Child Adolesc Psychiatry 19:353-364, 2010.

Graham J, Coghill D: Adverse effects of pharmacotherapies for attention-deficit hyperactivity disorder: Epidemiology, prevention and management. CNS Drugs 22:213-237, 2008.

Graham $\mathrm{J}$ et al. European guidelines on managing adverse effects of medication for ADHD. European Child Adolescent Psychiatry 20:17-37, 2011.

Greenhill LL, Vitiello B, Fisher P, Levine J, Davies M, Abikoff H, Chrisman AK, Chuang S, Findling RL, March M, Scahill L, Walkup J, Riddle MA: Comparison of increasingly detailed elicitation methods for the assessment of adverse events in pediatric psychopharmacology. J Am Acad Child Adolesc Psychiatry 43: 1488-1496, 2004.

Hale JB, Reddy LA, Semrud-Clikeman M, Hain LA, Whitaker J, Morley J, Lawrence K, Smith A, Jones N: Executive impairment determines ADHD medication response: Implications for academic achievement. J Learn Disabil 44:196-212, 2011.

Hammerness PG, Perrin JM, Shelley-Abrahamson R, Wilens TE: Cardiovascular risk of stimulant treatment in pediatric attentiondeficit/hyperactivity disorder: Update and clinical recommendations. J Am Acad Child Adolesc Psychiatry 50:978-990, 2011.

Hsieh HF, Shannon SE: Three approaches to qualitative content analysis. Qual Health Res 15:1277-1288, 2005.

Kovshoff H, Williams S, Vrijens M, Danckaerts M, Thompson M, Yardley L, Hodgkins P, Sonuga-Barke EJ: The decisions regarding ADHD management (DRAMa) study: Uncertainties and complex- ities in assessment, diagnosis and treatment, from the clinician's point of view. Eur Child Adolesc Psychiatry 21:87-99, 2012.

Meaux JB, Hester C, Smith B, Shoptaw A: Stimulant medications: A trade-off? The lived experience of adolescents with ADHD. J Spec Pediatr Nurs 11:214-226, 2006.

Medicines \& Healthcare Produces Regulatory Agency. Available at www.gov.uk/government/organisations/medicines-and-healthcareproducts-regulatory-agency

Murray ML, Insuk S, Banaschewski T, Neubert AC, McCarthy S, Buitelaar JK, Coghill D, Dittmann RW, Konrad K, Panei P, Rosenthal E, Sonuga-Barke EJ, Wong IC: An inventory of European data sources for the long-term safety evaluation of methylphenidate. Eur Child Adolesc Psychiatry 22:605-618, 2013.

National Institute for Health and Clinical Excellence: Attention Deficit Hyperactivity Disorder: Diagnosis and management of ADHD in children, young people, and adults. NICE guideline (CG72); 2008.

Pelham WE, Hoza B: Intensive treatment: A summer treatment program for children with ADHD. In: Psychosocial Treatments for Child and Adolescent Disorders: Empirically Based Strategies for Clinical Practice. Edited by Hibbs E, Jensen P. New York, APA Press, 1996, pp. 311-340.

Pringsheim T, Steeves T: Pharmacological treatment for Attention Deficit Hyperactivity Disorder (ADHD) in children with comorbid tic disorders. Cochrane Database Syst Rev CD007990, 2011

Ritchie J, Spencer L: Qualitative data analysis for applied policy research. In: Analysing Qualitative Data. Edited by Bryman A, Burgess R. London, Routledge, 1993, pp. 173-194.

Schachter HM, Pham B, King J, Langford S, Moher D: How efficacious and safe is short-acting methylphenidate for the treatment of attention-deficit disorder in children and adolescents? A metaanalysis. CMAJ 165:1475-1488, 2001.

Singh I, Kendall T, Taylor C, Hollis C, Batty M, Mears A, Keenan S: The experience of children and young people with ADHD and stimulant medication: A qualitative study for the NICE guideline. Child Adolesc Mental Health 16:186-192, 2010.

Solanto MV: Neuropharmacological basis of stimulant drug action in attention deficit disorder with hyperactivity: A review and synthesis. Psychol Bull 95:387-409, 1984.

Sprague RL, Sleator EK: Methylphenidate in hyperkinetic children: Differences in dose effects on learning and social behavior. Science 198:1274-1276, 1977.

Volkow ND, Wang G-J, Fowler JS, Telang F, Maynard L, Logan J, Gatley SJ, Pappas N, Wong C, Vaska P, Zhu W, Swanson JM: Evidence that methylphenidate enhances the saliency of a mathematical task by increasing dopamine in the human brain. Am J Psychiatry 161:1173-1180, 2004.

Address correspondence to: Edmund J.S. Sonuga-Barke, PhD Academic Unit of Psychology Developmental Brain Behaviour Laboratory Institute for Disorders of Impulse and Attention University of Southampton Southampton SO17 1BJ United Kingdom

E-mail: ejb3@soton.ac.uk 